\title{
Stage IV Hypopharyngeal Carcinoma AJCC v8
}

National Cancer Institute

\section{Source}

National Cancer Institute. Stage IV Hypopharyngeal Carcinoma A/CC v8. NCI Thesaurus. Code C133008.

Stage IV includes: IVA: (T4a, N0, M0); (T4a, N1, M0); (T1, N2, M0); (T2, N2, M0); (T3, N2, M0); (T4a, N2, M0); IVB: (Any T, N3, M0); (T4b, Any N, M0); IVC: (Any T, Any N, M1). T4a: Moderately advanced local disease. Tumor invades thyroid/cricoid cartilage, hyoid bone, thyroid gland, or central compartment soft tissue. Central compartment soft tissue includes prelaryngeal strap muscles and subcutaneous fat. T1: Tumor limited to one subsite of hypopharynx and/or $2 \mathrm{~cm}$ or smaller in greatest dimension. T2: Tumor invading more than one subsite of hypopharynx or an adjacent site, or measuring more than $2 \mathrm{~cm}$ but not more than $4 \mathrm{~cm}$ in greatest dimension without fixation of hemilarynx. T3: T umor larger than $4 \mathrm{~cm}$ in greatest dimension or with fixation of hemilarynx or extension to esophagus. T4b: Very advanced local disease. Tumor invades prevertebral fascia, encases carotid artery, or involves mediastinal structures. N0: No regional lymph node metastasis. N1: Tumor with metastasis in a single ipsilateral lymph node, $3 \mathrm{~cm}$ or smaller in greatest dimension and ENE (-). N2: Tumor with metastasis in a single ipsilateral lymph node, $3 \mathrm{~cm}$ or smaller in greatest dimension and $\mathrm{ENE}(+)$; or larger than 3 $\mathrm{cm}$ but not larger than $6 \mathrm{~cm}$ in greatest dimension and ENE(-); or metastases in multiple ipsilateral lymph nodes, none larger than $6 \mathrm{~cm}$ in greatest dimension and ENE(-); or metastases in bilateral or contralateral lymph nodes, none larger than $6 \mathrm{~cm}$ in greatest dimension and ENE(-). N3: T umor with metastasis in a lymph node larger than $6 \mathrm{~cm}$ in greatest dimension and ENE(-); or metastasis in a single ipsilateral lymph node larger than $3 \mathrm{~cm}$ in greatest dimension and $\mathrm{ENE}(+)$; or metastases in multiple ipsilateral, contralateral, or bilateral lymph nodes any with ENE(+). M0: No distant metastasis. M1: Distant metastasis. (AJCC 8th ed.) 